$14^{\text {th }}$ International Conference on

AEROSPACE SCIENCES \& AVIATION TECHNOLOGY,

ASAT - 14 - May 24 - 26, 2011, Email: asat@mtc.edu.eg Military Technical College, Kobry Elkobbah, Cairo, Egypt

Tel: +(202) 24025292-24036138, Fax: +(202) 22621908

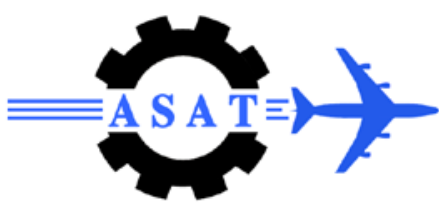

\title{
Determination of Natural Frequency of Anisotropic Plates Using D' Alembert Principle
}

\author{
Z. Almasri ${ }^{*}$, M. Younes ${ }^{\dagger}$, E. El-Soaly ${ }^{\ddagger}$
}

\begin{abstract}
A dynamic Analysis of thin rectangular plates made of anisotropic materials is treated. The analysis is based on the assumptions of classical plate theory in which the anisotropic characteristics of the plate material are introduced. The static lateral load on the plate is replaced by $\mathrm{D}^{\prime}$ Alembert inertia load. The free vibration of simply supported rectangular orthotropic plates is treated as numerical examples, the obtained results are compared with the three dimensional elasticity solution. To verify the theoretical analysis, an experimental study is done using 8 layers woven cross play fiber glass/epoxy rectangular plates.
\end{abstract}

Keywords: Natural Frequency, D' Alembert Principle, Anisotropic Materials, Plate theory, Tensorial Formulation.

\section{Nomenclature}

$\begin{array}{ll}\text { a, b, h } & \text { Plate length, width, and thickness. } \\ C_{i j k l} & \text { Generalized elastic moduli. } \\ D_{\alpha \beta \gamma \delta} & \text { Flexural rigidities. } \\ \text { i,j,k,l } & \text { Three dimensional tensorial indices. } \\ M_{\alpha \beta} & \text { Bending moments. } \\ \mathrm{q} & \text { Statical lateral load. } \\ \mathrm{t} & \text { Time variable. } \\ u_{\alpha} & \text { In-plane displacements. } \\ \mathrm{w} & \text { Plate deflection. } \\ x_{i} & \text { Cartesian coordinates. } \\ \alpha, \beta, \gamma, \delta=1,2 & \text { Two dimensional tensorial indices. } \\ ()_{, \alpha}=()^{, \alpha} & \text { Derivative with respect to } x_{\alpha} . \\ \varepsilon_{i j} & \text { Strain tensor. } \\ \lambda & \text { Eigen value. } \\ \rho & \text { Mass of unit area. } \\ \sigma_{i j} & \text { Stress tensor. } \\ \psi_{\alpha} & \text { Inclination angles. } \\ \omega & \text { Angular frequency. }\end{array}$

\footnotetext{
*Libyan Armed Forces, Libya, almasri_med@yahoo.com

† Egyptian Armed Forces, Egypt, myounes27@yahoo.com .

${ }^{\ddagger} 10^{\text {th }}$ of Ramadan Higher Institute of Technology, Egypt, eldessouky@hotmail.com
} 


\section{Introduction}

In the last decades, classical plate theory has been improved by introducing transverse shear deformations and rotary inertia. In the classical plate theory, longitudinal stresses are assumed to vary linearly across the plate thickness, Zak et al. [1] studied numerical and experimental investigation of free vibration of multilayer delaminated composite beams and plates. Cook [2] presented a finite element analysis based on Reissner's variational principle to calculate vibration and buckling Eigen value of isotropic rectangular plates. Khedeir and Reddy [3] obtained a complete set of linear equations of the second order theory to analyze the free vibration behavior of cross-ply and antisymmetric angle-ply laminated plates. Civalek [4] developed a numerical method for the free vibration analysis of symmetrically laminated composite plates. The procedure is based on the application of the discrete singular convolution (DSC) method in conjunction with the first-order shear deformation theory (FSDT). Thai and Kim [5] presented free vibration of laminated composite plates using two variable refined plate theory. The theory accounts for parabolic distribution of the transverse shear strains through the plate thickness, and satisfies the zero traction boundary conditions on the surfaces of the plate without using shear correction factors. Morozov and Lopatin [6] proposed an analytical closed-form solution providing the value of fundamental frequency of the composite sandwich plate. The variational equations of motion are derived using Hamilton's principle in conjunction with the first-order shear deformation theory. Most of innovative materials has some kind of anisotropy, monoclinic orthotropic or, transverse isotropic. Static and dynamic analysis of rectangular plates made if anisotropic materials have been treated by many authors, their analysis variational analysis or finite element approach. In the present analysis a dynamic analysis of anisotropic plates based on assumptions of classical plate theory is given. Highly anisotropic material, such as monoclinic one in which the material has only one plane of symmetry can be treated, the governing equation are presented in a compact for using tensor notations. The obtained statical equation of equilibrium is used to develop the Eigen values of free vibration of anisotropic plates. The lateral load $q$ in statical analysis may be replaced by D 'Alembert load $\left(-\rho \frac{\partial w^{2}}{\partial t^{2}}\right)$ where $\rho$ is the mass per unit area. Applications to orthotropic rectangular plates are given. The obtained results are compared with exact elasticity solution, given by Srinivas and Rao [7] and the classical plate theory. Instead of using the simplified classical assumptions, the results of present analysis are more accurate than those of the classical plate theory.

The accuracy tends to be better as the plate tends to be thicker. To verify the obtained theoretical analysis, an experimental work is done using 8-layers of fiber glass/epoxy woven cross-play laminates. Two sets of rectangular plates are used in experimental work, four edges simply supports boundary conditions are used. The material properties are determined using $3 \mathrm{~mm}$ electrical strain gages. The experimentally obtained Eigen values of free vibration of used plates are compared with that of the present theoretical analysis and exact solution.

\section{Governing Equations}

Generalization of Hooke's Law can be expressed in the form

$\sigma_{i j}=\left[C_{i j k l}\right] \varepsilon_{k l}$

For a material having one plane of symmetry (monoclinic).

$\sigma_{\alpha \beta}=C_{\alpha \beta \gamma \delta} \varepsilon^{\gamma \delta}+C_{\alpha \beta 33} \varepsilon^{33}$ 
$M_{\alpha \beta}=\int_{-h / 2}^{h / 2} \sigma_{\alpha \beta} \cdot z d z$

Substitution of equation (2) into (3) and for homogeneous monoclinic plate under lateral load $\mathrm{q}\left(x_{1}, x_{2}\right)$ Figure 1 , the generalization of classical plate theory analysis leads to the following expression for bending moments $M_{\propto \beta}$ by:

$M_{\propto \beta}=D_{\propto \beta \gamma \delta} \psi^{\gamma, \delta}$

where:

$D_{\alpha \beta \gamma \delta}=\frac{h^{3}}{12}\left(C_{\alpha \beta \gamma \delta}-\frac{C_{\alpha \beta 33} C_{\gamma \delta 33}}{\left.C_{3333}\right)}\right) \quad$ Flexural Rigidities.

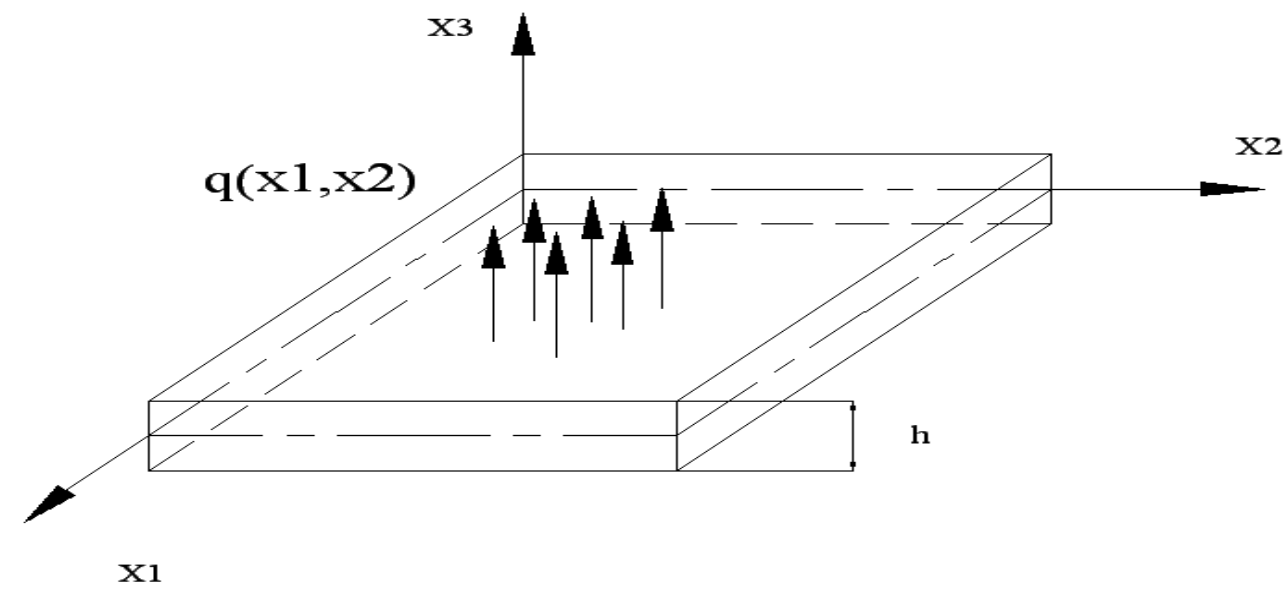

Fig. 1 Plate notation.

The inclination angles $\psi_{\alpha}$ and the deflection $\mathrm{w}$ are functions of the in-plane variables $x_{1}, x_{2}$. The quantities $C_{i j k l}$ are the three dimensional elastic moduli defined by the generalized Hooke's Low in equation (1).

Introducing the expression of the stress resultants $M_{\alpha \beta}$ and $Q_{\alpha}$ into the known equilibrium equations:

$M_{\alpha \beta, \beta}-Q_{\alpha}=0$

$Q_{\alpha, \alpha}+q=0$

A set of equilibrium equations in terms of $\psi_{\alpha}$ and $\mathrm{w}$ is obtained in the following form:

$D_{\alpha \beta \gamma \delta} \psi^{\alpha, \beta \gamma \delta}+q=0$

If the lateral load $\mathrm{q}$ is replaced by the $\mathrm{D}^{\prime}$ Alembert inertia load $\left(-\rho w_{, t t}\right)$ where $\rho$ is the mass per unit area of the plate and $t$ is the time variable, then the equilibrium equation (6) is transformed to the following equation of motion for a homogeneous monoclinic plates:

$D_{\alpha \beta \gamma \delta} \psi^{\alpha, \beta \gamma \delta}-\rho w^{, t t}=0$

The substitution of the relation $\psi_{\alpha}=w^{, \alpha}$, into equation (7) leads to the following equation:

$D_{\alpha \beta \gamma \delta} w^{\alpha \beta \gamma \delta}-\rho w^{t t}=0$ 


\section{Application to rectangular thick orthotropic plates}

Let us consider the free vibration of a rectangular orthotropic plate is simply supported at its four edges, Fig 2.

In this case the boundary condition may be expressed in the form

$$
\begin{aligned}
& \text { at } \quad x_{1}=0, x_{1}=a ; M_{11}=w=\psi_{2}=0, \\
& \text { at } \quad x_{2}=0, x_{2}=b ; M_{22}=w=\psi_{1}=0 .
\end{aligned}
$$

This set of edge conditions are identically satisfied by choosing $w$ in the form

$w=e^{I \omega t} \sum_{m=1}^{\infty} \sum_{n=1}^{\infty} w_{m n} \sin M x_{1} \sin N x_{2}$

where $\omega$ is the angular frequency of free vibration, $w_{m n}$ are undetermined coefficients,

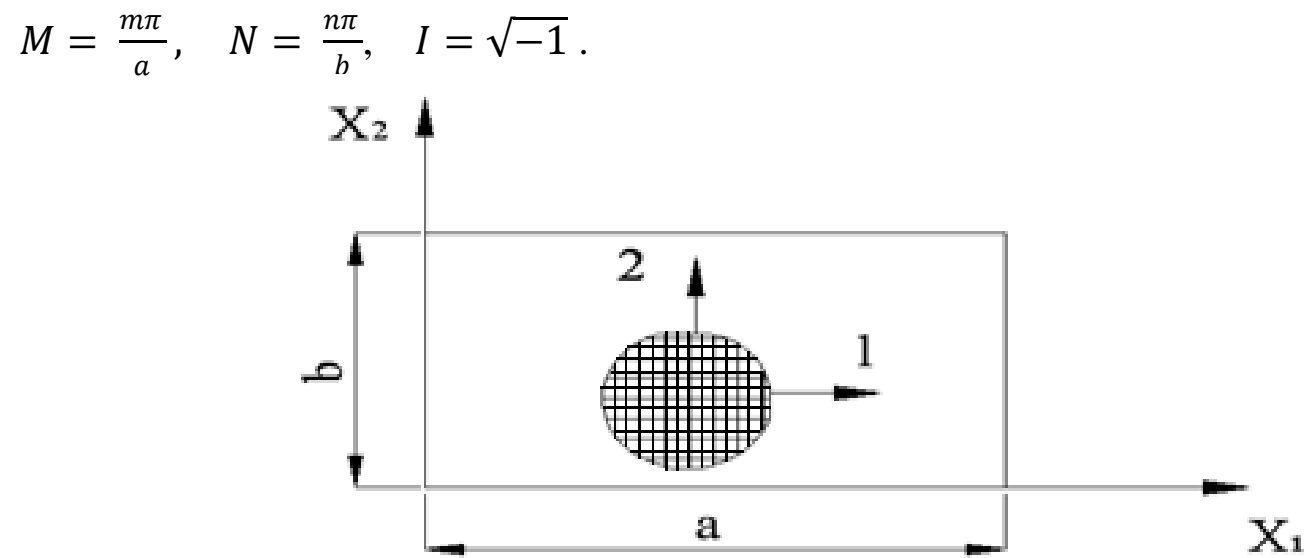

Fig. 2 Simply supported rectangular orthotropic plate.

For simple harmonic, the substitution of the expressions (9) into equation (7) yields for each combination of $\mathrm{m}$ and $\mathrm{n}$, the following equation for angular frequency $\omega$ :

$M^{4} D_{1111}+2 M^{2} N^{2} D_{1122}+4 M^{2} N^{2} D_{1212}+N^{4} D_{2222}-\rho \omega^{2}=0$

The Eigen value of free vibration $(\lambda)$ can be expressed in term of angular frequency $\omega$ as:

$\lambda^{2}=\omega^{2} \rho h / C_{1111}$

If the engineering elastic moduli of an orthotropic plate $\left(E_{11}, E_{22}, G_{12}, v_{12}\right)$ are known, the nonzero elements of the flexural rigidities $D_{\alpha \beta \gamma \delta}$ can be expressed as

$$
\begin{aligned}
D_{1111} & =\frac{h^{3} E_{11}}{12\left(1-v_{12} v_{21}\right)}, & D_{1122} & =\frac{h^{3} v_{12} E_{22}}{12\left(1-v_{12} v_{21}\right)}, \\
D_{2222} & =\frac{h^{3} E_{22}}{12\left(1-v_{12} v_{21}\right)}, & D_{1212} & =\frac{h^{3}}{12}\left(G_{12}\right) .
\end{aligned}
$$

The engineering constants are usually obtained from experimental test data or using fiber and mixture properties in micromechanical analysis and lamination theories. 


\section{Numerical Results and Discussion}

As a numerical example, the free vibration of a homogeneous orthotropic, simply supported rectangular plate is analyzed.

Consider the material properties given in Table 1, which simulate aragonite crystals [7].

Table 1 Orthotropic properties of aragonite crystals.

\begin{tabular}{c|l}
\hline \hline$C^{*}{ }_{2222}=0.543103$ & $C^{*}{ }_{3333}=0.530172$ \\
\hline$C^{*}{ }_{1122}=0.233190$ & $C^{*}{ }_{1133}=0.010776$ \\
\hline$C^{*}{ }_{2233}=0.089276$ & $C^{*}{ }_{1212}=0.262931$ \\
\hline$C^{*}{ }_{1313}=0.0159914$ & $C^{*}{ }_{2323}=0.266810$ \\
\hline$C^{*}{ }_{i h j k}=C_{i h j k} / C_{1111}$ &
\end{tabular}

Table 2 Eigen value $(\lambda)$ for free vibration of simply supported rectangular orthotropic plates.

\begin{tabular}{|c|c|c|c|c|c|c|c|}
\hline \multirow{2}{*}{ Case } & \multirow{2}{*}{$\frac{m h}{a}$} & \multirow{2}{*}{$\frac{n h}{b}$} & \multirow{2}{*}{$\begin{array}{c}\text { Exact } \\
\text { value [6] }\end{array}$} & \multicolumn{2}{|c|}{ Present analysis } & \multicolumn{2}{|c|}{ Thin plate theory } \\
\hline & & & & Value & \% error & Value & \% error \\
\hline \multirow{4}{*}{1} & 0.5 & 0.1 & 0.45265 & 0.72567 & 60 & 0.73374 & 62.10 \\
\hline & 0.5 & 0.2 & 0.48680 & 0.77007 & 58.2 & 0.79809 & 63.95 \\
\hline & 0.5 & 0.3 & 0.54160 & 0.84895 & 56.7 & 0.90459 & 67.02 \\
\hline & 0.5 & 0.4 & 0.61465 & 0.96707 & 57.3 & 1.05260 & 71.25 \\
\hline \multirow{4}{*}{2} & 0.1 & 0.5 & 0.42124 & 0.53533 & 27 & 0.54574 & 29.56 \\
\hline & 0.2 & 0.5 & 0.46428 & 0.59897 & 29 & .63418 & 36.59 \\
\hline & 0.3 & 0.5 & 0.52956 & 0.71518 & 35 & 0.78011 & 47.31 \\
\hline & 0.4 & 0.5 & 0.61092 & 0.89067 & 45.7 & 0.98269 & 60.85 \\
\hline \multirow{4}{*}{3} & 0.3 & 0.1 & 0.21804 & 0.27061 & 24.1 & 0.27789 & 27.45 \\
\hline & 0.3 & 0.2 & 0.26240 & 0.31815 & 21.4 & 0.34176 & 30.22 \\
\hline & 0.3 & 0.4 & 0.42242 & 0.53827 & 27.4 & 0.59313 & 40.41 \\
\hline & 0.3 & 0.5 & 0.52956 & 0.71518 & 35 & 0.78011 & 47.31 \\
\hline \multirow{5}{*}{4} & 0.1 & 0.1 & 0.04742 & 0.04511 & 4.8 & 0.04967 & 4.74 \\
\hline & 0.2 & 0.2 & 0.16942 & 0.18047 & 6.5 & 0.19866 & 17.26 \\
\hline & 0.3 & 0.3 & 0.33200 & 0.40606 & 22.3 & 0.44699 & 34.64 \\
\hline & 0.4 & 0.4 & 0.51342 & 0.72188 & 40.6 & 0.79466 & 54.78 \\
\hline & 0.5 & 0.5 & 0.70338 & 1.12795 & 60.3 & 1.24160 & 76.52 \\
\hline
\end{tabular}

In Table 2 the results for Eigen value are compared with the exact value [7] and thin plate theory. Plates with different aspect ratios are considered. Figure 3 presents a schematic diagram of percentage error in our analysis for different plate aspect ratios. It may be observed that the error in the present analysis decreases as the plate becomes thicker and narrower and maximum error for square plate. This error may be reduced by including the transverse shear stress. 


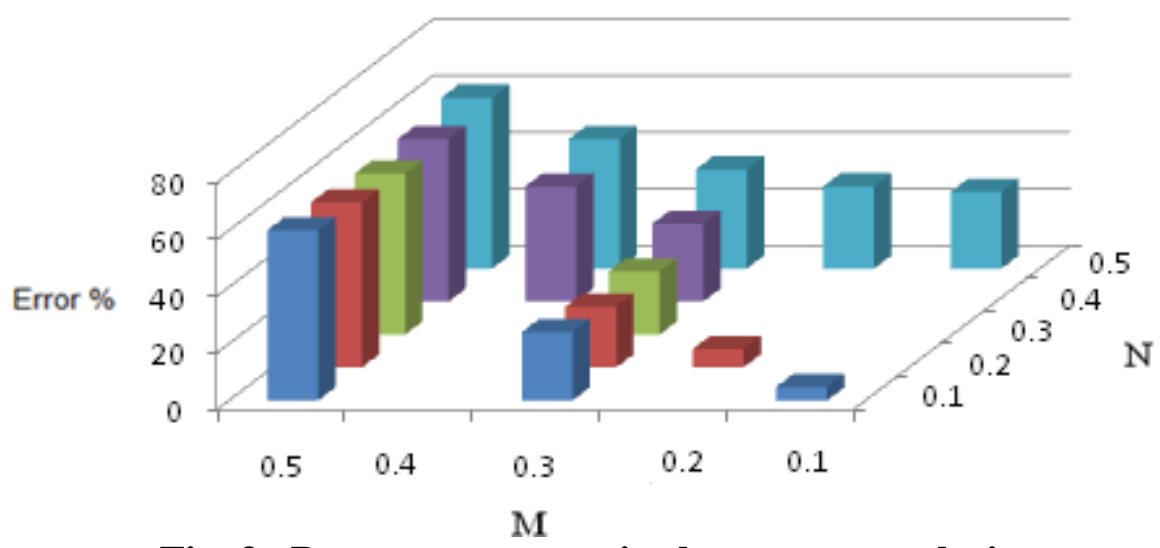

Fig. 3 Percentage errors in the present analysis for different plate aspect ratios.

\section{Experimental Work}

A sensitivity experimental analysis is carried out to study the natural frequency of a composite plate with deferent specimen dimensions and compared with the present method.

\subsection{Materials}

The following constituent materials were used for fabricating the composite plates: Glass woven fiber as reinforcement, Epoxy as resin.

\subsection{Equipment and Test Procedure}

The composite plate specimens used in this research were made from 0/90 woven glass fiber with epoxy matrix. Specimens were fabricated by hand lay-up technique and cured under room temperature.

The percentage of fiber and matrix is $50 \%$ in weight. The plates were left for a minimum of 48 hours before being transported and then cut to exact shape for testing of three rectangular plates and three square plates of dimensions (200X140X3, 140X140X3) mm, are prepared. The material constants $\left(E_{11}, E_{22}, G_{12}, v_{12}\right)$ of woven fiber Glass/Epoxy composite plate were determined experimentally by performing unidirectional tensile tests on specimens cut in longitudinal and transverse directions, and at $45^{\circ}$ to the longitudinal direction using material test system machine as relevant to ASTM Standard Fig.4. The shear modulus $\left(G_{12}\right)$ was determined using the formula from Jones [8]. Then natural frequencies were determined for all specimens with boundary condition (simply supported).The excitation was provided by impact hammer and the response was picked up by accelerometer fixed above the plate. The natural frequencies are obtained from the Dual Channel Dynamic signal analyzer.

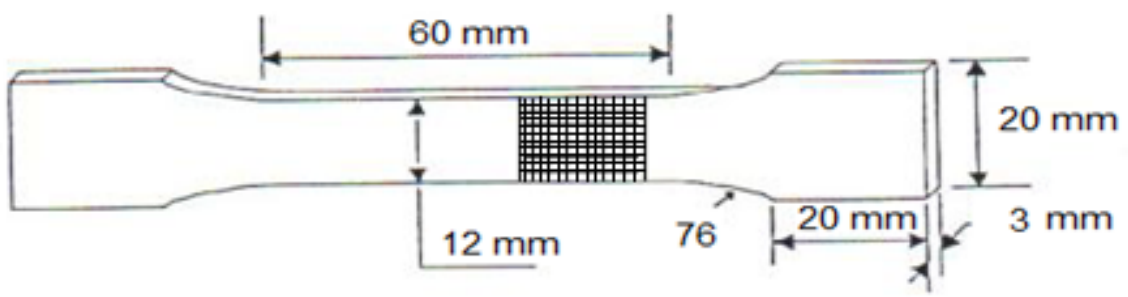

Fig. 4 Tensile test specimen dimensions 


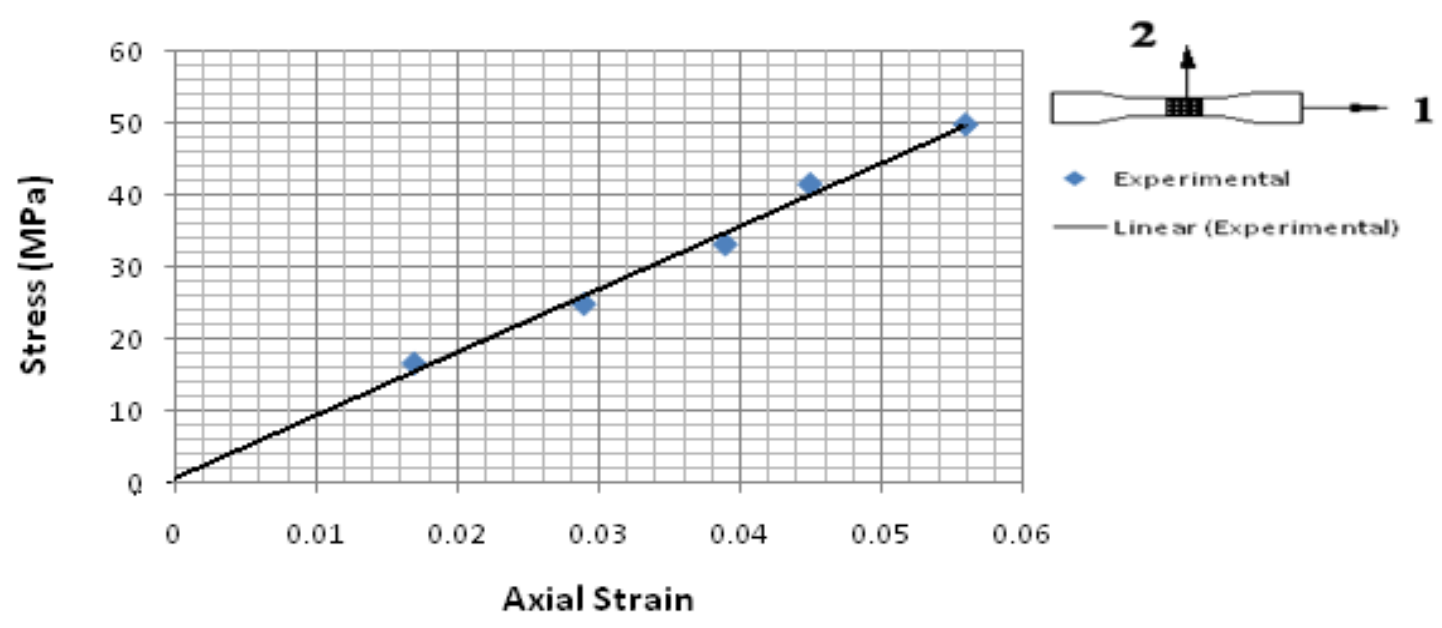

Fig. 5 Stress strain curve (load in fiber direction 1)

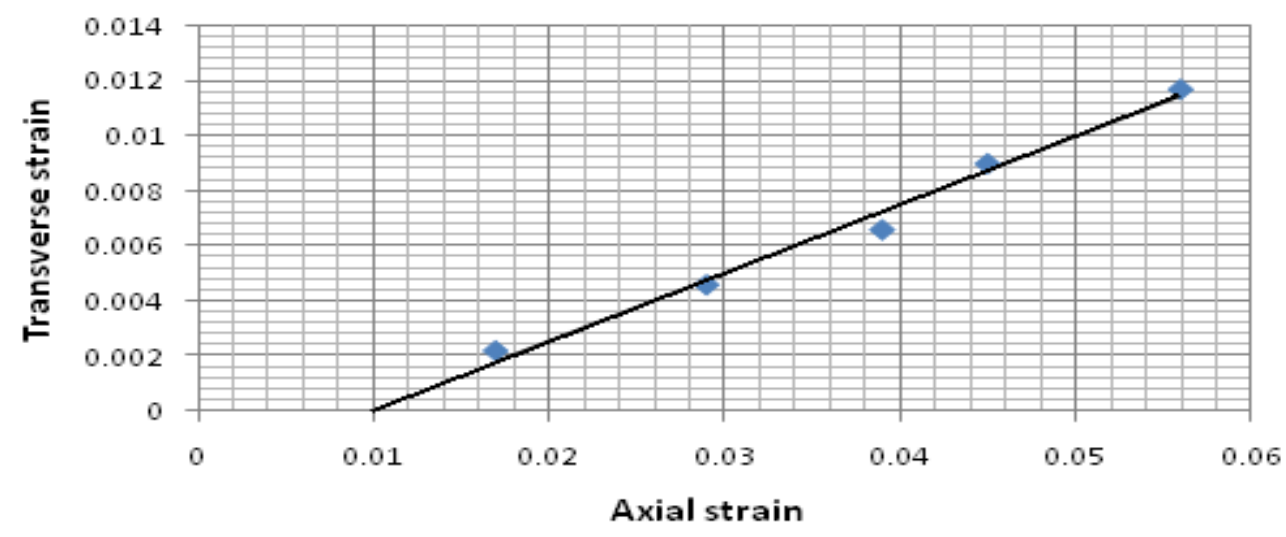

Fig. 6 Transverse strain versus linear strain

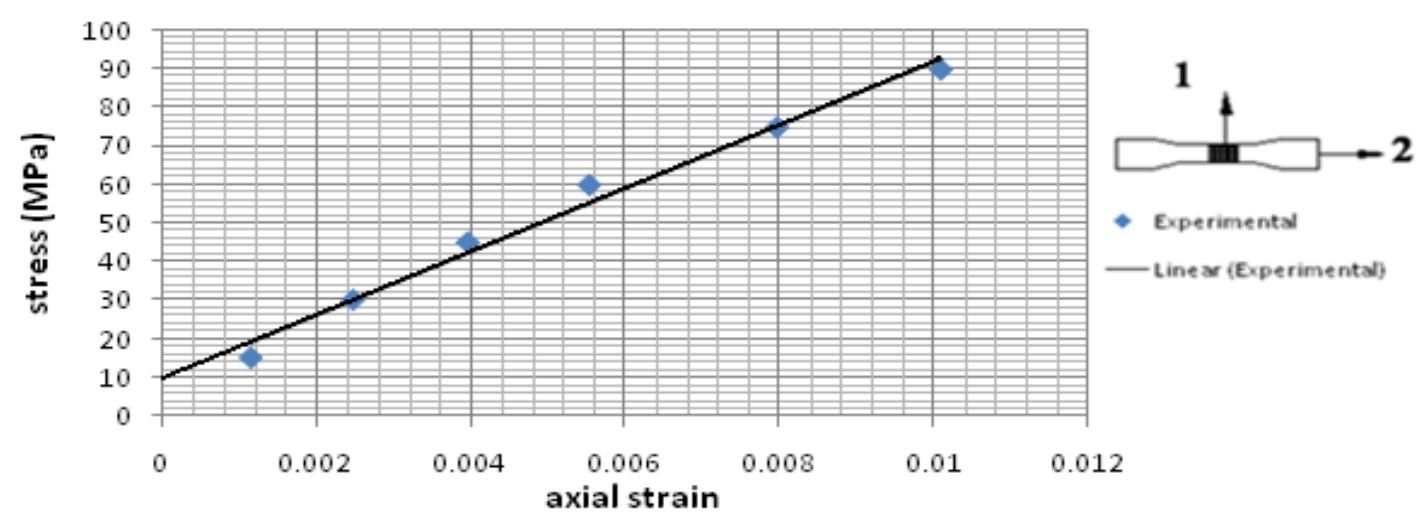

Fig. 7 Stress strain curve (load in fiber direction 2) 


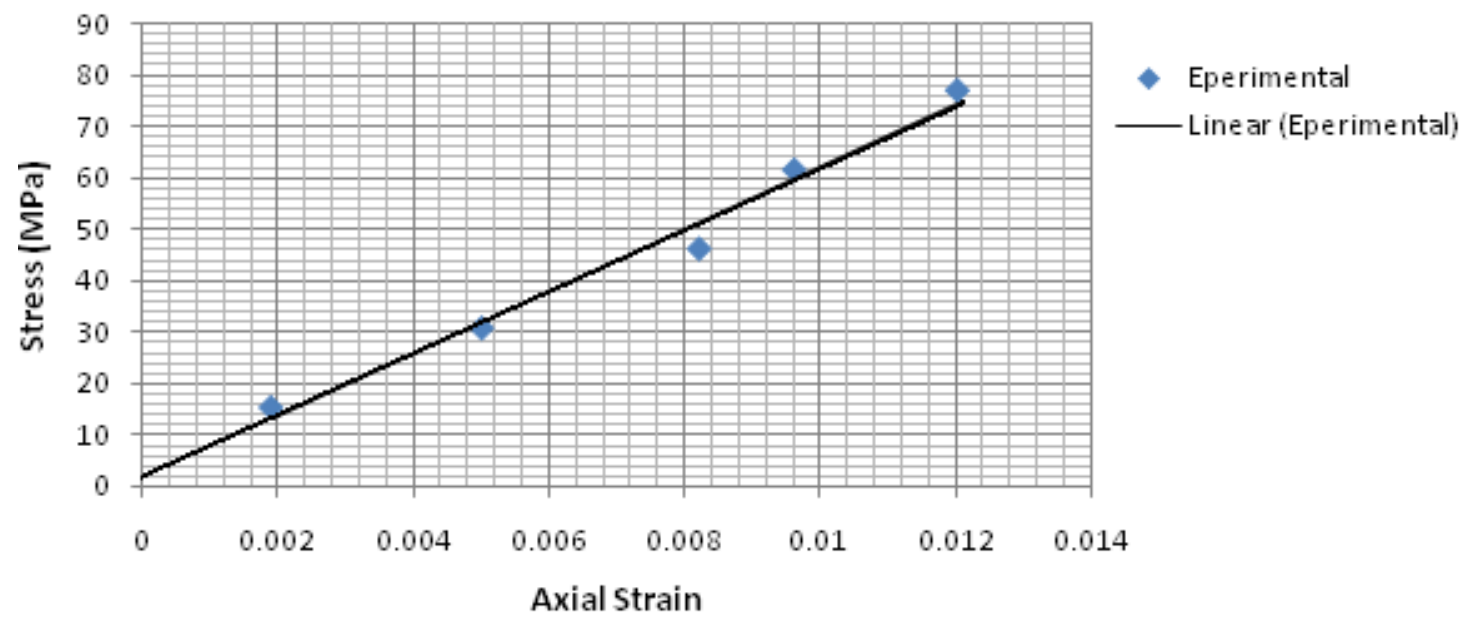

Fig. 8 Stress strain curve (load at $45^{\circ}$ to fiber direction 1,2$)$

\section{Model 1}

A square plate of dimension $(140 \times 140 \mathrm{~mm})$ length and of $(3 \mathrm{~mm})$ thickness made of woven fiber glass/epoxy.

Properties obtained from previous experimental tests:

$E_{11}=9 \mathrm{GPa}, E_{22}=9 \mathrm{GPa}, v_{12}=0.245, \quad v_{21}=0.266$

$G_{12}=2 G P a, \quad \rho=4.11 \mathrm{~kg} / \mathrm{m}^{2}$

Table 3 presents the Experimental Natural frequencies $(\mathrm{Hz})$ of woven fiber glass/epoxy square plate with a side length of $140 \mathrm{~mm}$ and a total thickness of $3 \mathrm{~mm}$.

Table 3 Natural frequencies of square plate specimen

\begin{tabular}{c|c}
\hline \hline Specimen & Natural Frequency $(\mathrm{Hz})$ \\
\hline 1 & 309 \\
\hline 2 & 302 \\
\hline 3 & 314.26 \\
\hline Avg & 308.4 \\
\hline \hline
\end{tabular}

\section{Model 2}

A rectangular plate of dimension $(200 \mathrm{~mm}, 140 \mathrm{~mm})$ and $(3 \mathrm{~mm})$ thickness made of woven fiber glass/epoxy.

Properties obtained from previous experimental tests:

$E_{11}=9 \mathrm{GPa}, E_{22}=9 \mathrm{GPa}, v_{12}=0.245, \quad v_{21}=0.266$

$G_{12}=2 \mathrm{GPa}, \quad \rho=4.11 \mathrm{~kg} / \mathrm{m}^{2}$

Table 4 represents the experimental natural frequencies $(\mathrm{Hz})$ of woven fiber glass/epoxy rectangular plate with a side length of $200 \mathrm{~mm}$ width $140 \mathrm{~mm}$ and a total thickness of $3 \mathrm{~mm}$. 
Table 4 Natural frequencies of rectangular plate specimen

\begin{tabular}{c|c}
\hline \hline Specimen & Natural Frequency $(\mathrm{Hz})$ \\
\hline \hline 1 & 238.9 \\
\hline 2 & 234.37 \\
\hline 3 & 233 \\
\hline Avg & 235.4 \\
\hline \hline
\end{tabular}

Comparison between experimental and theoretical natural frequencies showed good agreement as could be drawn from Table 5.

Table 5 Frequency comparison between experimental and theoretical analysis.

\begin{tabular}{c|c|c|c}
\hline \hline Model & $\begin{array}{c}\text { Present analysis } \\
(\mathrm{Hz})\end{array}$ & $\begin{array}{c}\text { Experimental analysis } \\
(\mathrm{Hz})\end{array}$ & Error \% \\
\hline \hline Square plate & 335.26 & 308.42 & 8.7 \\
\hline Rectangular plate & 252.68 & 235.4 & 7.34 \\
\hline \hline
\end{tabular}

\section{Conclusion}

In this paper a dynamic analysis of anisotropic plates based on assumptions of classical plate theory is given. Highly anisotropic material, such as monoclinic one in which the material has only one plane of symmetry can be treated. Numerical results of the Eigen value for laminates with simply supported boundary conditions are computed and compared with the published works, exact elasticity solution and the classical plate theory. The results of present analysis are more accurate than those of the classical plate theory. An experimental work is done using 8-layers of fiber glass/epoxy woven cross-play laminates. The material properties are obtained using the tensile test. The experimentally obtained natural frequencies of free vibration of used plates are compared with that of the present theoretical analysis and the results are in a good agreement.

\section{References}

[1] Zak. A., Krawczuk, M. and Ostachowicz, W.(2000) "Numerical and Experimental Investigation of Free Vibration of Multilayer Delaminated Composite Beams and Plates”, Comput. Mech., 26, pp 309-315.

[2] Cook, R.D. "Eigen Value Problems with a Mixed Plate Element" J. AIAA, vol.7, No 5, 1969, pp.982-983.

[3] Khdeir AA, Reddy JN. "Free Vibrations of Laminated Composite Plates Using SecondOrder Shear Deformation Theory", Compos. Struct 1999;71:617-26.

[4] Omer Civalek ,"Free Vibration Analysis of Symmetrically Laminated Composite Plates with First-Order Shear Deformation Theory (FSDT) by Discrete Singular Convolution Method", Finite Elements in Analysis and Design 44 (2008) 725 - 731, June 2008.

[5] Huu-Tai Thai, Seung-Eock Kim, "Free Vibration of Laminated Composite Plates Using Two Variable Refined Plate Theory", International Journal of Mechanical Sciences 52 (2010) 626-633, January 2010. 
[6] E.V. Morozov a, A.V. Lopatin, "Fundamental Frequency of the CCCF Composite Sandwich Plate”, Composite Structures 92 (2010) 2747-2757, April 2010.

[7] Srinivas S. and Rao A.K. "Bending Vibration and Buckling of Simply Supported Thick Orthotropic Plates and Laminates" J. Solid Structure, vol. 6,1970,pp. 1463-1481.

[8] R.M. Jones, Mechanics of Composite Materials, (1975), McGraw Hill, New York. 